\title{
The Molteno Implant in Intractable Glaucoma
}

\author{
R N DOWNES, ${ }^{1}$ D W FLANAGAN,${ }^{1} \mathrm{~K}$ JORDAN, ${ }^{2}$ and R L BURTON ${ }^{1}$ \\ Cambridge
}

\section{Summary}

The long term results in ninety-six cases of intractable glaucoma managed with the Molteno seton are presented. Over $\mathbf{5 0} \%$ of cases achieved satisfactory intraocular pressure control and visual stabilisation.

Treatment of glaucomas unresponsive to conventional therapy has until recently been singularly disappointing.

Treatment options available for these intractable glaucomas fall into two groups; those reducing aqueous production and those enhancing aqueous outflow.

Cyclocryotherapy and similar procedures aimed at ciliary body destruction and consequent reduction of aqueous production produce variable results. Whilst intraocular pressure can be controlled this appears to be at the expense of visual function, with total loss of vision occurring in between $30 \%$ and $60 \%$ of cases. As a result of this dismal prognosis, attention has recently been focussed on methods of alternative pathways for aqueous drainage.

Reports of assisted drainage of aqueous have been made since the beginning of the century with employment of a wide variety of ingenious, but generally unsuccessful, materials and methods. ${ }^{1,2,3,4}$ Although the concept of enhanced drainage is not new, practical implementation has only recently gained acceptance, with the Molteno short tube implant ${ }^{5}$ leading the way for further drainage implant development. ${ }^{6,7,8}$ by:

Aqueous may be re-routed in three ways

(1) the use of implants to maintain cyclodialysis clefts.
(2) the use of certain materials and/or implants to enhance or prolong the effect of conventional filtration procedures.

(3) the use of translimbal tubes connecting the anterior chamber to the sub-conjunctival or sub-tenons spaces.

Translimbal devices have steadily gained widespread acceptance; the majority of currently used implants fall into this category. The earlier short tube implants of Molteno and Krupin suffered a high failure rate from overlying external bleb scarring. ${ }^{6,7,9,10}$ The current generation of long tube implants are designed to obviate this problem by draining aqueous to a site, either equatorially or post equatorially, which is distant from the area of the conjunctival scarring induced by implant surgery.

We have used the single plate long tube Molteno implant in over 110 cases of intractable glaucoma and present the long-term results from 1979 to 1986 .

\section{Material and Methods \\ Patients}

To date we have used 119 single plate implants in 114 eyes of 106 patients: 65 of the patients were male, 41 female. The ages ranged from 6 years to 86 years. We have identified five groups of patients requiring surgery for intractable glaucoma, as outlined (Tables I to V).

From the ${ }^{1}$ Department of Ophthalmology, Addenbrookes Hospital, Cambridge and ${ }^{2}$ The Department of Ophthalmology, The Princess of Wales Royal Air Force Hospital, Ely, Cambridge.

Correspondence to: R N Downes FRCS, Department of Ophthalmology, Addenbrookes Hospital, Cambridge 
Table I Intractable Glaucomas

Neovascular

Non-neovascular
Neovascular glaucoma arising from diabetic retinopathy (DM)

Neovascular glaucoma secondary to retinal vein occlusion (RVO)

Congenital glaucoma (CONG.)

Secondary glaucoma $\left(2^{\circ}\right)$

Glaucoma associated with complex retinal detachment requiring vitrectomy and silicone oil (RD)

Table II Patient Details - Group Analysis

\begin{tabular}{llccrcc}
\hline & Group & $\begin{array}{c}\text { Total } \\
\text { Patients }\end{array}$ & $M$ & $F$ & $\begin{array}{c}\text { Age Range } \\
\text { (years) }\end{array}$ & $\begin{array}{c}\text { Average } \\
\text { (years) }\end{array}$ \\
\hline 1. & DM & 32 & 20 & 12 & $22-80$ & 50 \\
2. & RVO & 18 & 10 & 8 & $28-86$ & 62 \\
3. & CONG. & 11 & 4 & 7 & $6-24$ & 16 \\
4. & $2^{\circ}$ & 32 & 19 & 13 & $13-81$ & 41 \\
5. & RD & 13 & 12 & 1 & $22-71$ & 42 \\
\hline & Total & 106 & 65 & 41 & $6-86$ & 44 \\
\hline
\end{tabular}

Table III Congenital Glaucoma

$$
\begin{aligned}
11 \text { Patients } & -8 \text { Buphthalmos } \\
& -2 \text { Aniridia } \\
& -1 \text { Mesodermal dysgenesis }
\end{aligned}
$$

Table IV Secondary Glaucoma

\section{(32 Patients)}

10 Traumatic

6 Aphakic

4 Juvenile Pauciarticular Arthritis

3 Congenital Cataracts

2 Post-penetrating keratoplasty

- keratoconus

- herpes simplex keratitis

1 Iris cyst

1 Sturge Weber

5 Not categorised

Eighty-three patients with 96 implants have been followed up for a minimum period of six months, ranging from 6 to 87 months (Table VI).
Table V Retinal Detachment

13 Patients

All patients 2-4 pre-implant retinal detachment operations

4 patients pre-implant cataract surgery

1 patient pre-implant drainage surgery

5 patients - silicone oil removed pre-implant

Table VI Duration of follow up in months

\begin{tabular}{lcr}
\hline Group & Average & Range \\
\hline 1. DM & 32 & $7-87$ \\
2. RVO & 25 & $6-52$ \\
3. CONG & 31 & $19-48$ \\
4. $2^{\circ}$ & 33 & $8-72$ \\
5. RD & 20 & $8-36$ \\
\hline
\end{tabular}

\section{Treatment Objectives}

The patients can be divided into two categories. The larger group comprised patients in whom the aim was maintenance of visual function commensurate with lowering of intraocular pressure. The smaller group 
required pain amelioration consequent upon lowering of intraocular pressure. All patients in this group requested retention of their blind eyes. The majority of patients with neovascular glaucoma were on maximal antiglaucoma medication. Some had had previous drainage surgery. They all had uncontrolled glaucoma. All of the patients with congenital and secondary glaucoma had previous glaucoma surgery ranging from conventional drainage surgery to cyclocryotherapy. The majority were on combination anti-glaucoma therapy and all again were uncontrolled. The cases of glaucoma associated with complex retinal problems had all had previous conventional detachment surgery followed by vitreo-retinal surgery and silicone oil infusion. Silicone oil removal was necessary in several cases; this had no significant effect on the intraocular pressure. All were on antiglaucoma therapy with poor pressure control at the time of surgery.

\section{The Implant}

The single plate long tube Molteno implant comprises a translimbal silicone tube $(16 \mathrm{~mm}$ long; internal diameter $0.3 \mathrm{~mm}$; external diameter $0.63 \mathrm{~mm}$ ) attached to a circular acrylic plate $13 \mathrm{~mm}$ in diameter, the rim of which is perforated for the insertion of scleral fixation sutures. The tube opens onto the upper surface of the plate. Details of the mechanism have been extensively outlined by previous workers. ${ }^{9,10,11,12,13,14}$

\section{Procedure}

All operations were performed under general anaesthetic. The majority of operations were performed by four consultants. A further seven surgeons of varying levels of experience and expertise operated on the remainder of the cases.

The method used for implanting the Molteno seton in early cases was that advocated by Molteno..$^{5,10}$ As experience accrued with the implant, variations in plate and tube positioning evolved in an attempt to minimise some of the complications encountered.

The supero-nasal quadrant was the preferred site for implant fixation but it was occasionally necessary to site the implant in one of the other quadrants. The plate was usually fixed to the sclera equatorially or further posteriorly using non-absorbable sutures through the two anterior plate perforations. In patients with an existing encircling element it was sited posterior to the encirclement with the tube overlying the encircling band.

The majority of tubes were inserted directly into the anterior chamber but in two post-retinal detachment aphakic patients the tube was positioned in the posterior chamber via a pars plana sclerotomy. The most favoured means of covering the silicone tube was a scleral tunnel and trabeculectomy flap combination but a continuous scleral tunnel was sometimes used.

All the outlined alterations in basic technique had no demonstrable effect on the final outcome of the procedure.

Particular attention was paid to positioning of the tube in the anterior chamber with respect to both tube angulation and length. The former was controlled by careful angulation of the paracentesis aiming to align the tube parallel with the iris plane; the latter by trimming the tube to just the required length, taking care not to shorten it excessively. In most cases this entailed a limbal overlap of 2$3 \mathrm{~mm}$ as measured with the implant plate attached to the globe before positioning the tube. The antifibrosis regime described by Molteno was abandoned after the first few cases. $^{12}$

Topical steroids and mydriatics were employed routinely for several weeks postoperatively. Additional topical therapy, such as a beta blocker, was used as required.

\section{Results}

Ninety-six cases have been followed up for at least six months. The pre-operative intraocular pressures are detailed (Table VII).

Using the criteria outlined (Table VIII) satisfactory intraocular pressure control was achieved in $58 \%$ of cases with stabilisation or improvement of visual acuity in 52\%.

Satisfactory intraocular pressure control was achieved in between $50 \%$ (congenital glaucoma group) and 67\% (retinal detachment and diabetic groups) of eyes (Tables IX and $\mathrm{X}$ ). Satisfactory and stable vision occurred in between $40 \%$ (diabetic group) and 
Table VII Pre Operative Intraocular Pressures $(\mathrm{mmHg})$

\begin{tabular}{lcl}
\hline \multicolumn{1}{c}{ Group } & Average & \multicolumn{1}{c}{ Range } \\
\hline 1. DM & 43 & $20-73$ \\
2. RVO & 49 & $28-70$ \\
3. CONG & 37 & $21-55$ \\
& & $(2$ below 28) \\
4. $2^{\circ}$ & 41 & $14-59$ \\
& & $(1$ below 28) \\
5. RD & 35 & $12-40$ \\
& & $(1$ below 28) \\
\hline
\end{tabular}

Table VIII Classification of Results

\begin{tabular}{|c|c|}
\hline \multicolumn{2}{|c|}{ Intraocular Pressure } \\
\hline Success & $\begin{array}{l}\text { - IOP of } 20 \mathrm{~mm} \mathrm{Hg} \text { or less } \\
\text { - without additional treatment } \\
\text { - non phthisical eye }\end{array}$ \\
\hline Partial success & $\begin{array}{l}\text { - IOP of } 25 \mathrm{~mm} \mathrm{Hg} \text { or less } \\
\text { - with or without additional } \\
\text { treatment } \\
\text { - non phthisical eye }\end{array}$ \\
\hline Failure & - all other cases \\
\hline \multicolumn{2}{|l|}{ Visual Acuity } \\
\hline Success & $\begin{array}{l}\text { - visual acuity maintained or } \\
\text { improved }\end{array}$ \\
\hline Partial success & $\begin{array}{l}\text { - stable and useful VA (H.M. 1m } \\
\text { or better) }\end{array}$ \\
\hline Failure & - all other cases \\
\hline
\end{tabular}

$67 \%$ (congenital glaucoma group) of eyes (Tables XI and XII).

Patients requiring more than one implant and those blind pre-operatively account for the smaller number of cases available for visual assessment. The former were categorised only according to the final visual acuity; the latter were not categorised.

Seven of the 32 diabetic patients had preimplant pan-retinal photocoagulation, 12 had pre-implant intracapsular cataract extractions and 3 had lensectomies.

Five of the 18 patients with vein occlusions had pre-implant photocoagulation.

All of the patients with retinal detachments had between 2 and 4 pre-implant retinal detachment procedures.

All cases of congenital glaucoma had previous surgery - between two and nine (with an average of four) intraocular procedures per eye.

The procedure was not without complications (sic). These ranged from self limiting and minor problems to total loss of vision (Table XIII).

\section{Discussion}

We believe this study to be the single largest long-term analysis of drainage implants used in the treatment of intractable glaucoma in the United Kingdom.

The single plate Molteno implant was first used in Cambridge in 1979 following promising results reported by Molteno. ${ }^{5,10}$ It has

Table IX Results: Intraocular Pressure

\begin{tabular}{lcccc}
\hline Group & Number & Success & Partial Success & Failure \\
\hline $1 . \mathrm{DM}$ & 30 & 13 & 7 & 10 \\
2. RVO & 15 & $43 \%$ & $23 \%$ & 8 \\
3. CONG & 13 & $20 \%$ & $27 \%$ & 5 \\
$4.2^{\circ}$ & 26 & 1 & $7 \%$ & 13 \\
5. RD & 12 & 7 & $6 \%$ & 4 \\
& & $67 \%$ & $23 \%$ & 4 \\
\hline Total & 96 & $50 \%$ & $17 \%$ & 40 \\
& & 30 & 26 & \\
\hline
\end{tabular}


been used, to date, in over 110 cases; we present the long-term results with 96 implants in 83 patients.

The majority of eyes in this study were severely compromised as a result of both the underlying disease process and the effects of multiple surgical procedures. Whereas a success rate of less than $50 \%$ in the context of treatment for primary open angle glaucoma would be unacceptable, it may well be acceptable in intractable glaucoma with the alternative of a blind and/or painful eye. A success rate of over $50 \%$ with both intraocular pressure control and visual acuity is therefore most encouraging and certainly compares favourably with recent studies using a variety of drainage implants. $7,8,9,14,15,16,17,18,19,20,21$

Consideration of visual acuity shows that a successful outcome is significantly less likely in the neovascular glaucomas. This does not relate directly to intraocular pressure control but appears to be due more to the continuing disease process. A relatively small percen-

Table X Intraocular Pressure

\begin{tabular}{lc}
\hline & Success and partial success \\
\hline 1. DM & $67 \%$ \\
2. RVO & $47 \%$ \\
3. CONG. & $62 \%$ \\
4. $2^{\circ}$ & $50 \%$ \\
5. RD & $67 \%$ \\
Overall & $58 \%$ \\
\hline
\end{tabular}

tage of the cases in the earlier part of this study had satisfactory laser photocoagulation, either pre- or post-operatively. Laser retinal photocoagulation is often difficult since many patients have opacities of the media and dilate poorly; yag laser sphincterotomy and the panfundoscope lens may be helpful in some cases. Aggressive treatment with adequate retinal photocoagulation appears to improve the success rate of implant surgery. Twelve patients in this series were treated with pan retinal photocoagulation; $75 \%$ achieved satisfactory intraocular pressure control and $50 \%$ stable vision.

The majority of failures occurred in eyes with a pre-operative visual acuity of 'counting fingers' or less. A further breakdown of 27 cases with pre-operative visual acuity between $6 / 5$ and $1 / 60$ shows that although vision has been lost in some of these cases the majority have retained navigational vision or better (Fig 1 and 2). Figure 3 illustrates that some patients have obtained significant visual improvement following surgery.

With regard to intraocular pressure there is again variation in implant efficacy within the sub-groups. Satisfactory pressure control was achieved in only $47 \%$ of the vein occlusion group compared with $67 \%$ of the diabetic group. The reason for this difference is unclear.

The three cases of total loss of vision resulting directly from surgery were all related to suprachoroidal haemorrhage. Two of these eyes had previous complicated and

Table XI Results: Visual Acuity

\begin{tabular}{lcccc}
\hline Group & Number & Success & Partial Success & Failure \\
\hline $1 . \mathrm{DM}$ & 30 & 7 & 5 & 18 \\
& & $23 \%$ & $17 \%$ & 7 \\
2. RVO & 12 & 1 & 4 & 3 \\
3. CONG. & 9 & $8 \%$ & 0 & 3 \\
$4.2^{\circ}$ & 21 & $67 \%$ & 12 & 8 \\
$5 . \mathrm{RD}$ & 11 & $57 \%$ & $6 \%$ & 4 \\
& & $55 \%$ & $9 \%$ & 40 \\
\hline Total & 83 & 32 & 11 & \\
\hline
\end{tabular}


multiple retinal detachment surgery. The third was the fellow eye of one of these patients with co-existing intractable glaucoma on which multiple intraocular procedures had been performed. One of these eyes had a visual acuity of $6 / 36$ pre-opera-

Table XII Visual Acuity

\begin{tabular}{lc}
\hline & Success and partial success \\
\hline 1. DM & $40 \%$ \\
2. RVO & $42 \%$ \\
3. CONG. & $67 \%$ \\
4. 2 & $62 \%$ \\
5. RD & $64 \%$ \\
Overall & $52 \%$ \\
\hline
\end{tabular}

Table XIII Complications

Immediate

Flat/shallow anterior chamber

Hyphaema

Corneal oedema - localised

$$
\text { - generalised }
$$

Sterile uveitis and hypopyon

Acute cataract

Malignant glaucoma

Choroidal detachment

Expulsive haemorrhage

Endothelial touch

Blockage of tube - fibrin/blood

$$
\begin{aligned}
& \text { - iris } \\
& \text { - vitreous }
\end{aligned}
$$

\section{Delayed}

Localised corneal oedema

Corneal decompensation

Endophthalmitis

Repeated hyphaema

Persistent uveitis

Transpupillary membrane

Cataract

Persistent hypotony

Retinal detachment

Delayed expulsive haemorrhage

Superficial infection over implant

Implant extrusion/erosion

Tube block - iris

- vitreous

Tube retraction/migration tively but the other two had very poor preoperative vision. Suprachoroidal or expulsive haemorrhage is a well reocgnised, albeit rare,

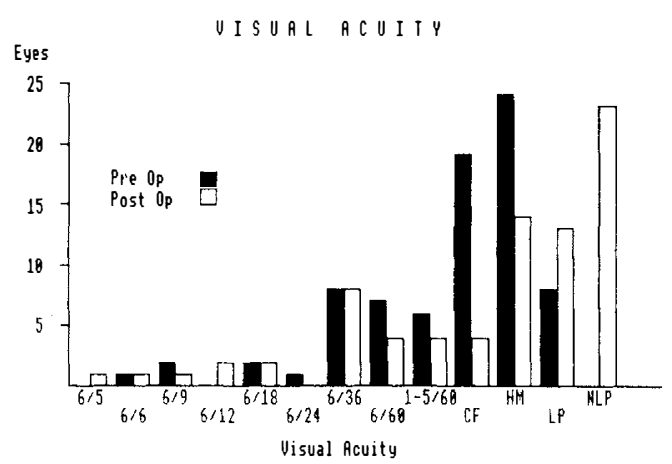

Fig. 1.

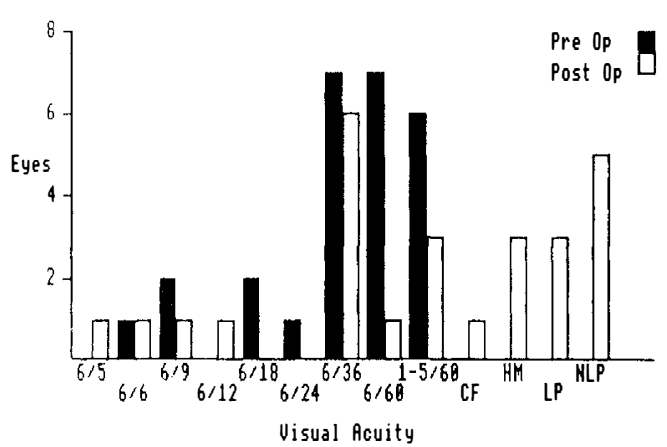

Fig. 2.

\section{EYES WITH POST OP UA BETWEEN 6/5 AND $1 / 60$}

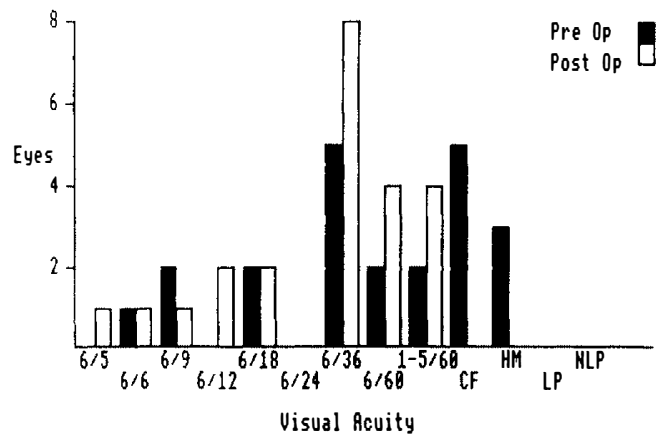

Fig. 3. 
complication following intraocular surgery, particularly drainage operations. It occurs more often in significantly comprised eyes as all of these undoubtedly were. The majority of eyes progressing to total visual loss, however, were not affected in this way. The visual loss resulted primarily from the continuing disease processes rather than the surgery itself.

The occurrence of hyphaema and a shallow or flat anterior chamber was extremely common, but it usually settled spontaneously over the first few post-operative days; only rarely did clot organisation present a problem requiring surgical or laser intervention. Anterior chamber shallowing occurred immediately post-operatively and lasted for anything up to 10 days, although the usual duration of this complication was between 46 days. In the great majority of cases this appeared to be of limited import but in some eyes it was associated with tube-endothelial touch and/or choroidal detachment. Prolonged hypotony is associated with more serious complications notably cataract formation and this has been reported following many drainage implants. Various attempts to solve this problem have recently been made. A pressure sensitive outflow valve has been incorporated into certain implants. Molteno suggests that anterior chamber shallowing can be obviated by two-stage surgery. ${ }^{9,14} \mathrm{We}$ feel a six to eight week delay combined with toxic antifibrosis therapy is not in the best interest of our patients.

Healonid $^{\mathrm{R}}$ has been used to fill the anterior chamber and silicone tube of the implant. The size and angulation of incision into the anterior chamber through which the silicone tube passes needs careful control. Whilst these measures delay the onset of the problem they do not prevent its occurrence. To date we have no experience with using a suture to limit temporarily aqueous outflow. It should be noted that shallowing of the anterior chamber may be inherent in the operative procedure and therefore management should be aimed at minimising both the duration and severity of this problem.

Blockage of the silicone tube with blood, iris or vitreous was seen in $13 \%$ of eyes. Tube plugging was usually transient with spontane- ous resolution following anterior chamber reformation. Occasionally limited surgical or laser intervention was needed.

There was a $10 \%$ incidence of local corneal touch with associated corneal oedema. In the majority of cases this was transient, disappearing with anterior chamber reformation. Persistence of tube touch necessitated tube shortening in one case. Eleven eyes developed significant localised or general corneal decompensation.

Failure to control intraocular pressure was seen in $24 \%$ of eyes and was related to either alteration of the position of the implant or failure of satisfactory bleb formation. Early drainage failure was seen in $11 \%$ of cases: 3 eyes as a result of tube retraction and 7 eyes with unsatisfactory bleb formation. The incidence of the latter did not appear to be increased as a result of omission of anti-fibrosis therapy. Further, it did not appear to be dependent on the type of glaucoma nor the age of the patient. Bleb failure appeared more likely with proximity of the plate to conjunctival and Tenon's capsule tissue scarred from previous disease, trauma or surgery. For this reason we advocate positioning of the plate as far posteriorly as possible on the globe, preferably in a quadrant untouched by previous surgery or trauma. Late drainage failure occurred in $13 \%$ of eyes and resulted either from implant extrusion/ erosion or tube retraction/migration, but repositioning or replacement of the tube was successful in controlling intraocular pressure in some cases.

Following surgery, the first three months appeared to be critical. After this period and barring infection the majority of implants continued to function satisfactorily. Comparison with other methods of treatment is difficult. We know from past observations and experience that if these or similar eyes are left without treatment, blindness with or without severe pain eventually ensues. Conservative treatment in the form of topical preparations, usually comprising a steroid and mydriatic combination, is very helpful in keeping these eyes comfortable, although retrobulbar alcohol or even enucleation may be necessary. This treatment is only palliative. Cyclocryotherapy or cyclodestructive 
processes may be used in the management of intractable glaucoma. These modalities act by reducing aqueous production consequent upon variable ciliary body destruction. In addition to the theoretical objection of increasing the concentration of vasoformative substances within the anterior chamber in cases of neovascular glaucoma, these procedures have a high incidence of serious complications. $^{22}$ Cataract, anterior segment ischaemia, phthisis and blindness are commonly reported. In a recent series of patients undergoing cyclocryotherapy, $59 \%$ of patients lost light perception after treatment. ${ }^{22}$ Conventional filtration procedures are disappointing in established neovascular glaucoma for two reasons. Continuing proliferation of fibrovascular tissue invariably blocks off the internal opening of the fistula. Bleb fibrosis causes a similar obstruction to flow at the external opening of the fistula. In all cases of non-neovascular glaucoma in this series conventional filtration surgery was either unsuccessful $(65 \%)$ or deemed inappropriate $(35 \%)$.

Direct comparison of published results can be misleading. Variability exists regarding acceptable levels of intraocular pressure and follow-up duration. Visual acuity is of paramount importance to the patient but is often afforded scant regard in the literature.

The pre-operative condition of the eye is obviously of great importance. This factor is very difficult to quantify but implant failure is more likely in a severely compromised eye. Current studies reveal great variation regarding both the primary disease process and ensuing surgical and medical manipulations. What constitutes success in terms of subsequent procedures on the eyes is also subject to different interpretation. The criteria adopted for categorisation of intraocular pressure levels are more rigid than those used by some other workers. Unlike some reports we have classified all cases requiring a second implant as a primary failure regardless of the eventual outcome with respect to intraocular pressure.

Despite these problems, analysis of and comparison with other studies is most valuable. The short tube Krupin-Denver valve has been used with some success. External bleb scarring, however, resulted in failure in $28 \%$ of cases. ${ }^{10}$ Consequently the standard tube has been modified to a long tube implant incorporating a pressure sensitive valve which drains under a circumferential silastic band. This design is felt to obviate the problem of external bleb fibrosis. The success rate in controlling intraocular pressure is quoted as between $65 \%$ and $70 \%$ with the standard tube rising to between $80 \%$ and $85 \%$ of 45 eyes with the modified implant. ${ }^{19}$ These results are certainly impressive although it has taken several modifications of the basic implant design to reach this level of success. We cannot directly compare our results with these since the criteria for an acceptable intraocular pressure differ somewhat.

Molteno has had considerable success using initially the single plate and, more recently, the two and four plate Molteno implants. ${ }^{9,10,13,14} \mathrm{He}$ advocates surgery as a two-stage procedure with the use of a potent combination of medications designed to minimise bleb fibrosis. $9,10,14$ We have found the undeniably toxic anti-fibrosis regime seemingly unnecessary in the vast majority of cases. Indeed, early experience at Cambridge showed a higher failure rate occurred with patients on this regime! ${ }^{12}$ The intraocular pressure was controlled in 56 out of 96 eyes $(58 \%)$ without using systemic Colchicine, Prednisolone and Fluphenamic acid. Only 7 tubes failed from primary bleb failure. Use of the anti-fibrotic regime might conceivably have prevented these failures. At best this would have improved the success rate from $58 \%$ to $66 \%$ (63 out of 96 eyes). We feel that this possible improvement does not justify subjecting a patient to the serious systemic side-effects of Colchicine, Prednisolone and Fluphenamic acid. ${ }^{23,24}$ Post-operative hypotony, although worrying, was rarely of significance and on balance we feel that a second operation coupled with a two-month treatment delay is less acceptable than a temporarily shallow or flat anterior chamber. Molteno states that his two plate implant provides the best compromise between intraocular pressure control and significant hypotony, whilst reducing the need for medication to control bleb fibrosis. ${ }^{9,14}$ This does appear to 
offer theoretically, at least, some advantage over the single plate, and as such may be beneficial in certain 'high risk' patients. The earliest series from Molteno reported a $50 \%$ success rate using an intraocular pressure of $30 \mathrm{~mm}$ of mercury or less as acceptable. More recently he reports a greater success rate with a more acceptable intraocular pressure level cut-off. ${ }^{9,14} \mathrm{He}$ stresses the importance of adopting an aggressive management policy with regard to neovascular glaucoma and has obtained a significant improvement in his results to confirm this opinion. ${ }^{14}$

Schocket et al have recently described an innovative two piece drainage implant. Results are impressive although the nonneovascular glaucoma group is small. The authors cite a $96 \%$ success rate. ${ }^{15,16}$ Applying our criteria with regard to pressure control a success rate of $65 \%$ and partial success rate of an additional $15 \%$ is obtained. These authors encountered a high incidence of postoperative hypotony which they minimised operatively using a combination of hyaluronic acid within the anterior chamber and a smaller anterior chamber entry wound for the silastic tube. The surgical technique involved appears more complicated than implantation of the Molteno single plate seton. Marked conjunctival scarring and implantation in the presence of explants, especially an encircling band, would appear to introduce significant technical difficulties.

Hitchings et al have reported their experiences at Moorfields with the anterior chamber tube shunt to an encircling band in 35 eyes with unresponsive glaucoma followed up for at least one year. ${ }^{20}$ Forty-six per cent of the eyes had intraocular pressures controlled with a single operation; $46 \%$ however, required re-operation for uncontrolled pressures. They achieved an eventual success rate of $71 \%$ as defined by intraocular pressure less than $21 \mathrm{~mm}$ of mercury with or without treatment. To overcome the problem of early hypotony they suggested incorporation of a pressure sensitive valve into the system. This modification is now available as the Joseph valve implant. Joseph et al report their experience with 19 eyes using this implant. ${ }^{18,21}$ Eleven of these were followed up for six months or more. Two demonstrated significant and protracted hypotony, with over $50 \%$ of patients having a reduced visual acuity post-operatively.

\section{Conclusion}

There is as yet no ideal implant for the treatment of intractable glaucoma. All currently used implants have evolved following modifications of design and implant technique. Complications have been significantly reduced but not abolished. It should not be forgotten that all these eyes are severely compromised by the underlying pathological insult and subsequent surgical treatment, so that complications and failures of drainage implants are to be expected in some patients.

An aggressive management policy with early and adequate pan-retinal photocoagulation in the neovascular group will significantly reduce the incidence of neovascular glaucoma. If, however, intractable glaucoma occurs then the decision to implant should be taken early since the results both in terms of eventual pressure control and vision are better. This is even more apparent in the nonneovascular group.

Following implant surgery careful supervision and continuing treatment, with surgical or laser intervention if indicated, is obligatory. Systemic and potentially highly toxic antifibrosis medication appears unnecessary.

The single plate Molteno implant is a well tried and tested drainage device. It has the advantages of being readily available and easily implantable. Our experiences lead us to commend it for more widespread use by the generalist faced with the occasional patient with intractable glaucoma.

We wish to thank our colleagues Mr. J D Scott, Mr. P $\mathrm{G}$ Watson and Mr. J Keast-Butler for allowing us to include their cases in the series and for their advice in preparing this paper. We also thank Mrs. C D Bailey for typing the manuscript.

\section{References}

${ }^{1}$ Zorab J. The reduction of tension in chronic glaucoma. The Opthalmoscope. 1912, 10: 25861.

${ }^{2}$ Gibson GG. Transscleral lacrimal canaliculus transplants. Am. J. Ophthalmol. 1944, 27: 258-69.

3 Bock RH. Subconjunctival drainage of the 
anterior chamber by a glass seton. Am. J. Ophthalmol. 1950, 33: 929-39.

${ }^{4}$ Ellis RA. Reduction of intraocular pressure using plastics in surgery. Am. J. Ophthalmol 1960, 50: 733-42.

${ }^{5}$ Molteno ACB. A new implant for glaucoma clinical trial. Br. J. Ophthalmol. 1969, 53: 60615.

${ }^{6}$ Molteno ACB. The optimum design of drainage implants for glaucoma. Trans. Ophthalmol. Soc. NZ 1981, 33: 39-41.

${ }^{7}$ Krupin T, Kaufman P, Mandell A, Ritch R, Asseff C, Podos SM, Becker B. Filtering valve implant surgery for eyes with neovascular glaucoma. Am. J. Ophthalmol. 1980, 89: 338-43.

${ }^{8}$ Kuljaca Z, Ljubojevic V, Momirov D. Drainage implant for neovascular glaucoma. Am. J. Ophthalmol. 1983, 96: 372-76.

${ }^{9}$ Molteno ACB. Use of Molteno implants to treat secondary glaucoma. In Cairns JE. ed Glaucoma Vol. 1 London: Grune \& Stratton Ltd 1986: 211-38.

10 Molteno ACB, Van Rooyen MMB Bartholomew RS. Implants for draining neovascular glaucoma. Br. J. Ophthalmol 1977, 61: 120-25.

11 Cairns JE. The Molteno long-tube implant. Trans. Ophthalmol. Soc. UK 1983, 103: 3941.

${ }^{12}$ Brown RD and Cairns JE. Experience with the Molteno long tube implant. Trans Ophthalmol. Soc. UK 1983, 103: 297-312.

${ }^{13}$ Molteno ACB, Ancker E, Van Biljon G. Surgical technique for advanced juvenile glaucoma. Arch. Ophthalmol. 1984, 102: 51-7.

${ }^{14}$ Molteno ACB. Neovascular glaucoma - diag- nosis and therapy. In Cairns JE. ed Glaucoma Vol. 1 London: Grune \& Stratton Ltd 1986: 883-915.

15 Schocket SS, Lakhanpal V, Richards RD. Anterior chamber tube shunt to an encircling band in the treatment of neovascular glaucoma. Ophthalmology 1982, 89: 188-94.

16 Schocket SS, Nirankari VS, Lakhanpal V, Richards RD, Lerner BC. Anterior chamber tube shunt to an encircling band in the treatment of neovascular glaucoma and other refractory glaucomas - A long term study. Ophthalmology 1985, 92: 553-62.

${ }^{17}$ Freedman J. The use of the single stage Molteno long tube seton in treating resistant cases of glaucoma. Ophthalmic. Surg. 1985, 16: 480-3.

18 Joseph N, Sherwood M, Trantas G, Hitchings RA. One-piece drainage system for glaucoma surgery. Trans. Ophthalmol. Soc. UK 1986, 105: 657-64.

${ }^{19}$ Krupin T. Surgical treatment of glaucoma with the Krupin-Denver valve. In Cairns, JE. ed Glaucoma Vol. 1 London: Grune \& Stratton Ltd 1986: 239-46.

${ }^{20}$ Hitchings RA and Lattimer J. How to manage the unresponsive patient. Eye 1987, 1: 55-60.

21 Sherwood, MB, Joseph NH, Hitchings RA. Surgery for refractory glaucoma. Arch. Ophthalmol. 1987, 105: 562-9.

22 Krupin T, Mitchell KB, Becker B. Cyclocryotherapy in neovascular glaucoma. Am. J. Ophthalmol. 1978, 86: 24-6.

23 ABPI Data Sheet Compendium 1986-87. Datapharm Publications Ltd.

24 Martindale - The Extra Pharmacopoeia, Reynolds J. ed London. Med Pharmaceutical Press 1983. 